\title{
Considerações sobre a identidade do professor não nativo dentro da abordagem pelo Letramento Crítico e no contexto de inglês como língua global.
}

\section{Ana Raquel Fialho Ferreira Campos}

Doutoranda em Letras pela UFPR - Universidade

Federal do Paraná. Professora de Letras da

UNICENTRO - Universidade Estadual do Centro-

Oeste, Guarapuava; Paraná; Brasil.

anakelfer@yahoo.com.br

Resumo: Embora o inglês caminhe atualmente para o conceito de global e o Letramento Crítico esteja amplamente divulgado, o professor não nativo enfrenta o sentimento de inferioridade quando comparado ao nativo. Uma possível razão baseia-se na influência de países "avançados" sobre os demais sistemas educacionais impondo a língua inglesa dos EUA ou Inglaterra como norma. Este artigo discute a Síndrome do Impostor (BERNATT, 2008) e a identidade do professor de inglês (RAJAGOPALAN 2001, JORDÃO 2010, NORTON 2001). Essa discussão é considerada como auxiliadora na formação de professores, nas suas relações com o outro e na construção de suas crenças sobre si mesmos.

Palavras- chave: Inglês global; Letramento Crítico; Síndrome do Impostor
Abstract: Although English is increasingly being seen as a global language and Critical Literacy Approach is vastly disseminated, non native teachers face the feeling of insecurity and inferiority when compared to native teachers. Eventually because there is influence of "advanced" countries over other educational systems imposing the English from US or England as the standard norm (JORDÃO, 2008). This article aims at discussing the presence of the Impostor Syndrome (BERNATT, 2008) and the identity of the English teacher (RAJAGOPALAN 2001, JORDÃO 2010, NORTON 2001). This discussion is considered benefic to teaching training, to the teachers' relationship with others and to discuss teachers' beliefs about themselves.

Key words: English as a Global Language; Critical Literacy; the Impostor Syndrome 



\section{Introdução}

O intuito deste trabalho é discutir a posição do professor de inglês não nativo em um contexto no qual a língua inglesa está adquirindo o papel de língua global. Com este termo adquirir, não há intenção de afirmar que o inglês está se transformando em língua global, ou que todos os ingleses (Englishes) se tornarão globais, até porque estamos no meio deste processo e uma definição para o que está acontecendo exige um maior tempo de observações, conforme comenta Rajagopalan (2011). Neste contexto de mudanças encontra-se o professor não nativo, o qual se depara com a missão de equilibrar e adequar suas aulas aos novos moldes de ensino em que acredita. Esses moldes seriam os que propõem uma educação transcultural e aulas não voltadas apenas para o ensino da cultura americana ou inglesa.

\section{0 que é uma língua global?}

De acordo com Crystal (2010), o status de global é atingido por uma língua quando esta desenvolve um papel especial que é reconhecido em todos os outros países. Não é o número de falantes que decide se uma língua é global ou não, a língua deve ser tomada para uso em outros países, o que pode acontecer de duas formas: Na primeira, tornando-se uma língua oficial, como meio de comunicação em áreas especificas como negócios, política, etc. A segunda maneira, eventualmente, é a língua em questão tornar-se prioridade no ensino de língua estrangeira. Portanto, a característica de global está vinculada a quem são os falantes desta língua e não apenas ao o número de pessoas que a utiliza.

Existe uma forte conexão entre domínio linguístico e poder cultural, econômico e tecnológico. Assim, uma língua tem tradicionalmente se tornado global através do poder político e militar de seu povo. Como exemplo, 
podemos citar o grego, o latim, e o árabe, a primeira língua assumiu a posição de global através dos exércitos de Alexandre o Grande, a segunda ficou conhecida pelas legiões do Império Romano, e a terceira foi vastamente propagada através do islamismo levado pelos exércitos mouros. Esses exemplos criam um pano de fundo para a afirmação de que a história das línguas globais pode ser traçada juntamente com as expedições de sucesso de seus falantes (CRYSTAL 2010).

Hoje, dentro da década de 2010, o inglês é a língua estrangeira mais estudada e há mais falantes de inglês como língua global do que falantes nativos. Erroneamente, argumenta-se que a razão do inglês ser considerado a língua global é a sua facilidade de construções gramaticais, a sua simplicidade estrutural, no entanto, essa afirmação é questionada ao compararmos a língua inglesa com o latim, que, a despeito de toda a sua complexidade de flexões e diferenças de gênero, foi a língua dominante por um longo período.

Nos séculos XVII e XVIII o inglês foi a língua da nação colonizadora, a Inglaterra, nos séculos XVIII e XIX, o inglês foi a língua do líder da Revolução Industrial, novamente a Inglaterra. Por fim, no final do século XIX e início do século XX, o inglês foi a língua do líder econômico: os Estados Unidos.

Deacordo com Crystal(2010), os desenvolvimentos tecnológicos dos séculos XIX e XX foram responsáveis pela criação de novas opções de comunicação. O progresso da ciência e da tecnologia culminou no crescimento das organizações multinacionais, na explosão do mercado e da propaganda internacional, e no aumento do poder da imprensa. O império político britânico lançou o inglês pelo globo, o desenvolvimento econômico norteamericano e as relações cada vez mais estreitas entre comunidades linguisticamente diferentes colaboraram com a necessidade de uma língua global (CRYSTAL 2010). 
Algumas tentativas têm sido feitas para descrever as características básicas desta "nova língua", como no livro The Phonology of English and International Language (JENKINS 2000), no qual a autora foca no uso do inglês por falantes que não compartilham do mesmo histórico cultural ou linguístico e também levanta sua preocupação com a inteligibilidade mútua, seja qual for a língua materna. A autora parte do princípio de que a língua inglesa não é mais ensinada apenas com o intuito de possibilitar a comunicação entre falantes não nativos e falantes nativos, nem tampouco tem como objetivo desenvolver a pronúncia e sotaques de países específicos.

Uma possível solução para este conflito entre qual "inglês" deve ser ensinado, seria estabelecer um tipo de variedade simplificada, neutra, inteligível e aceita por falantes quer nativos quer não nativos, conforme propõe Gimson (1978 apud. JENKINS 2000). Uma segunda proposta, apresentada por Pennington (1996 apud. JENKINS 2000) é prover múltiplos modelos, tanto nativos quanto não nativos e ensinar normais gerais de acordo com a necessidade dos aprendizes, sem focar no padrão americano ou britânico. De acordo com Jenkins (2000), o objetivo é fluency e não accuracy, portanto, o significado e o contexto são mais importantes do que as regras gramaticais.

Concordo com a afirmação de que atualmente não aprendemos inglês para nos comunicarmos com nativos, mas sim com o mundo, concordo também com o fato de que mudando o objetivo do aprendizado muda-se o processo de ensino. No entanto, a criação ou transformação de um "novo" inglês, talvez mais simplificado (JENKINS 2000), ainda está plantada em um solo pedregoso. Consequentemente, acompanho Rajagopalan (2011) ao afirmar que ainda não há uma definição sobre qual caminho a língua inglesa irá seguir. 
Atualmente, com a expansão do inglês como língua global e a crescente exigência da língua inglesa no mercado de trabalho, há uma demanda por cursos de inglês que movimenta os donos e diretores de escolas de língua a competirem pelos seus alunos. Nessas competições, de acordo com Tatar \& Yildiz (2010), encontra-se os proprietários de centros de línguas explorando a concepção errônea de que o professor nativo é melhor do que o não nativo.

Trabalho como professora e coordenadora de um centro de línguas no interior do Paraná. Em meu local de trabalho, a valorização do professor nativo em detrimento do não nativo existe até os dias de hoje. Anualmente ao se tratar de novas contratações, a diretora da escola não deixa de mencionar a necessidade, termo utilizado por ela, de termos um professor nativo na escola, mais especificamente norte-americano. Aparentemente, o mercado das escolas de idiomas trabalha na contramão das reflexões da academia, pois podemos observar diariamente nas mídias sociais as diversas propagandas de escolas de inglês que colocam o fator "professor nativo" como decisivo no processo de aprendizagem de uma segunda língua. Sendo assim, enxergando através das lentes da publicidade e da propaganda, entendo a visão da diretora da escola de idiomas que faço parte.

A inclusão de um professor norte-americano em meu local de trabalho está prevista para o primeiro semestre de 2015 e terá a duração de cerca de 1 ano. Acredito que uma futura pesquisa sobre o impacto dessa contratação seria proveitosa para os estudos a respeito das crenças sobre professores nativos ou não nativos.

\section{Mudanças no ensino de Inglês.}

Segundo Jordão (2011), aprender inglês como língua global pode levar à construção de novas formas 
de saber, novas formas de pensar o desenvolvimento nacional e internacional e novas formas de relacionar países e culturas. Propostas têm sido feitas com o intuito de ir além da crença de que o falante nativo é o modelo a ser seguido, pois em um contexto como o atual, o nativo é apenas mais uma parte do grande grupo de falantes dessa língua (LLURDA, 2004). Ainda, o conceito de proficiência em inglês não é determinado por local de nascimento, mas pela capacidade de se usar a língua apropriadamente, capacidade que é compartilhada por um grupo de falantes quer sejam nativos ou não (CRYSTAL, 2010). Assim, o que hoje se procura é a habilidade de se comunicar em inglês com outros falantes não nativos que possuem diferentes línguas maternas (JENKINS, 1998).

Novas necessidades aparecem frente aos professores de EFL, dentre elas a liberdade em relação ao formato do nativo dominante no qual normas britânicas e americanas devem ser seguidas e os falantes nativos são considerados os professores ideais (LLURDA 2004). Este formato que segue os padrões dos países do norte ainda denomina o professor de inglês como embaixador da cultura inglesa ou norteamericana e esse professor se encontra na situação de ter que abrir mão de sua própria cultura para valorizar a cultura do outro. Mckay (2003 apud. LLURDA 2004) propõe criar oportunidades em sala de aula para o aluno compartilhar sua própria cultura com outros falantes de inglês, posto que essa é uma das oportunidades criadas a partir da habilidade de ser bilíngue. Dendrinos (2001 apud. LLURDA 2004) afirma que o ensino de inglês em contextos de EFL deve oportunizar o livre movimento entre L1 e L2 e vice-versa. A autora parte do fato de que os estudantes de inglês não serão monolíngues na língua recém adquirida, mas sim intérpretes ou ainda reportarão idéias concebidas na língua mãe. A sala de aula segundo Mckay (2003 apud. LLURDA 2004) deve proporcionar o exercício destas habilidades, o que contrapõe as idéias tradicionais da abordagem comunicativa, na qual 
${ }^{1}$ Conforme o texto original: "those of us who accept the notion of WE (World English) need to go back to the drawing board and rethink our entire approach to ELT. (...) ELT practices that have for long been in place need to be reviewd drastically with a view to addressing the new set of challenges being thrown at us by the phenomenon of WE, Up until now a good deal of our taken-forgranted ELT practices have been threatened with the prospect of being declared obsolete for the simple reason that they do not take into account some of the most significant characteristics of WE."(RAJAGOPALAN, 2004, P. 112) apenas a língua inglesa deve ser utilizada em sala. Esta questão do uso da língua materna em sala de aula merece discussão mais aprofundada para que a abordagem escolhida em sala de aula esteja de acordo com a concepção de língua entendida pelo professor.

A respeito do professor não nativo, destaco algumas questões neste trabalho. Vale considerar que o fato do professor não nativo ser a fonte bilíngue dentro de sala de aula o faz preparado para entender as exigências do momento de ensino ao ser capaz de alternar entre as duas línguas. No entanto, para que esse professor possa rejeitar perspectivas monoculturais e etnocêntricas ele deve estar pautado em uma pedagogia contemporânea de inglês como língua global, de acordo com Siqueira (2011 p. 108), "ele deve assumir sua condição mestiça, seu caráter local (...) constantemente (re) qualificado em programas de educação linguística fundados em abordagens críticas e transformadoras." Ainda sobre o professor, merece destaque a fala de Rajagopalan (2004, apud BERTO, P. L. 2011).

Aqueles de nós que aceitam a noção de WE (World English) precisam voltar à estaca zero e repensar toda a nossa abordagem de ensino de língua inglesa (...) Práticas de ensino que estão atuantes por muitos anos precisam ser revistas drasticamente com o olhar dirigido ao novo conjunto de desafios lançado sobre nós através do fenômeno do WE. Até agora uma grande parte de nossas práticas tomadas por certas tem sido ameaçadas com a perspectiva de serem declaradas obsoletas pela simples razão de que elas não levam em consideração algumas das mais significativas características do WE. (tradução minha) ${ }^{1}$

\section{Contribuições do Letramento Crítico}

O Letramento Crítico, doravante LC, pode ser o pano de fundo ideal para o ensino do inglês como língua 
global. Conforme Jordão (2011 p. 233), a preocupação principal do LC é o funcionamento das linguagens como espaços de construção de sentidos e formação de subjetividades, bem como a necessidade constante de desafiar pressupostos numa atitude de abertura permanente para desenvolver diferentes procedimentos interpretativos. O conceito de língua dentro do LC difere, e muito, do conceito tradicional, no qual a língua traduz e representa a realidade, ao passo que no LC a língua e a realidade constroem-se uma à outra. Onde antes a língua era apenas um meio de comunicação, no LC ela constrói a comunicação, antes comunicava idéias e valores, agora os cria. Se na noção tradicional a língua era neutra e transparente, agora ela é sempre culturalmente tendenciosa.

Neste novo entendimento a mudança está no pensamento sobre cultura, identidade, comunicação, saber, ética e conhecimento. (ANDREOTTI \& MARIO, 2006). No LC a língua não é concebida como código, mas sim como discurso, o que implica na construção de novos significados e identidades. Se concebermos a língua como discurso, a sala de aula torna-se o espaço ideal para discutir procedimentos de atribuição de sentidos ao mundo (JORDÃO e FOGAÇA, 2007), criando juntamente com os alunos a noção do inglês como língua global, minimizando o status linguístico dos países do norte. Dentro do ensino de línguas estrangeiras, o LC possibilita um aumento da compreensão de que as línguas são usadas de formas, conceitos e propósitos diferentes, bem como por pessoas diversas e por isso deve-se usar maneiras interpretativas também diversas construindo os possíveis sentidos (JORDÃO e FOGAÇA, 2007). Dentro do LC, o processo de significação é um processo não de codificação, mas sim de construção de significados a partir do texto. Conforme Jordão (2011), os alunos e professores de inglês como língua global podem tirar proveito dos conflitos 
criados pela multiplicidade de sentidos possíveis que nossa sociedade tenta homogeneizar, sentir-se à vontade na pluralidade (p. 235). Segue quadro 1 com o comparativo das tradições teóricas, dos objetivos e da compreensão do objeto de estudo no Ensino Comunicativo e no Letramento Crítico retirado do texto de Mattos e Valério, (2010).

\begin{tabular}{l|l|l}
\cline { 2 - 3 } & Ensino Comunicativo & Letramento Crítico \\
\hline Origens & $\begin{array}{l}\text { Filosofia da linguagem } \\
\text { Antropologia linguística } \\
\text { Linguística sistêmica }\end{array}$ & $\begin{array}{l}\text { Teoria social crítica } \\
\text { Pedagogia Crítica } \\
\text { Pós-estruturalismo }\end{array}$ \\
\hline Objetivos & $\begin{array}{l}\text { Desenvolvimento da } \\
\text { competência comunicativa } \\
\text { (usar para aprender e } \\
\text { aprender para usar) }\end{array}$ & $\begin{array}{l}\text { Desenvolvimento da } \\
\text { consciência crítica } \\
\text { (aprender para transformar) }\end{array}$ \\
\hline Visão de Língua & $\begin{array}{l}\text { Recurso dinâmico para a } \\
\text { criaçáo de significados }\end{array}$ & $\begin{array}{l}\text { Instrumento para a } \\
\text { reconstruçáo social }\end{array}$ \\
\hline Implementaçáo & $\begin{array}{l}\text { Promovido por atividades } \\
\text { que envolvem comunicação real. }\end{array}$ & $\begin{array}{l}\text { Promovido por um diálogo } \\
\text { que elicie a crítica social. }\end{array}$ \\
\hline
\end{tabular}

Quadro 1: Tradições teóricas, objetivos e compreensão do objeto de estudo no Ensino Comunicativo e no Letramento Crítico. (MATTOS e VALÉRIO, 2010)

Partindo da necessidade de discussão, reflexão e questionamento que existe dentro do LC, a língua materna tem um papel fundamental neste processo, mesmo dentro de uma sala de aula de língua estrangeira. A reflexão sobre o papel dos discursos, tanto da língua materna quanto da estrangeira, pode trazer à luz questões de extrema importância para o aprendiz, que, não havendo como serem tratadas apenas fazendo uso da língua estrangeira, tornam-se questionamentos guardados. Esses assuntos, como o valor educativo de se aprender uma LE, inclusão social, construção e representação de identidades sociais, a consciência do papel das línguas na sociedade, são capazes de iniciar um processo de transformação de crenças e abrir caminho para um aprendizado mais efetivo. $\mathrm{O}$ potencial de transformação de nossos procedimentos interpretativos, bem como as diferentes maneiras de 
adquirir o conhecimento e de ver o mundo, não podem ser silenciados dentro de sala de aula e precisam encontrar abertura para discussão.

\section{A Síndrome do Impostor}

Bernatt (2008) revela em sua pesquisa que a maioria dos professores não nativos de inglês não se sente confortável na posição de professor de uma língua que não é a sua de berço. Este sentimento caracteriza a Síndrome do Impostor (The Impostor Syndrome), explorada por Bernatt (2008). Essa síndrome é sentida por professores de inglês não-nativos desta língua, que, ao valorizarem demasiadamente o falante nativo como norma, questionam suas próprias posições dentro de sala de aula. Os sentimentos compartilhados por estes professores são, de acordo com Bernatt (2008), inadequação, inautenticidade, dúvida de si mesmo, ansiedade generalizada quando no papel de professor, e a percepção de que são apenas falantes de inglês com um alto ou baixo nível de sucesso.

Surge então um questionamento a respeito da posição do professor diante do contexto de inglês como língua global: Se não há o papel do falante nativo, uma vez que o inglês global é uma língua desterritorializada, também não haveria o sentimento de inferioridade ou inautenticidade por parte dos professores, já que não haveria professores de nacionalidades "superiores" para trabalharem com a língua inglesa.

Percebendo a necessidade de discussão, Bernatt (2009) tratou este assunto com professores não nativos de inglês em formação através de palestras ministradas ora por ela, ora por professores de inglês não nativos, que muniram estes alunos e professores de informações atualizadas sobre a direção do ensino de inglês, sobre inglês como língua global e sobre o fato de que o número 
${ }^{2}$ Conforme texto original: An 'interlanguage' may be linguistically described using as data the observable output resulting from a speaker's attempt to produce a foreign norm, i.e., both his errors and non-errors. Tradução livre.

${ }^{3}$ Conforme texto original: ... the real phenomenon of the permanent nonlearning of TL [target language] structures, of the cessation of IL [interlanguage] learning (in most cases) far from expected TL norms. Radução livre. de professores não nativos de inglês é muito superior ao número de professores nativos.

Uma das possíveis razões para o acontecimento desta Síndrome está no fato de que muitas publicações, que no passado serviram de base dentro da linguística aplicada, revelam a dependência existente em relação ao modelo nativo. A definição de Selinker (1969 apud MAHBOOB, 2010) para o termo interlíngua exemplifica a dependência do modelo nativo. Para ele, interlíngua é aquela que "pode ser linguisticamente descrita usando, como dado, a produção observada resultante da tentativa do falante em produzir uma norma estrangeira, isto é, tantos seus erros como acertos."2 Ainda Selinker (1992 apud MAHBOOB, 2010) define fossilização como $^{3}$, "o fenômeno real do permanente não aprendizado das estruturas da línguaalvo, da suspensão da interlíngua em um estágio longe das normas esperadas da língua-alvo. Conforme Mahboob (2010), essa metamorfose dos professores de inglês não nativos passarem de dependentes do modelo do falante nativo para independentes do modelo do falante nativo é relativamente recente e está longe de ser completa pois trata-se de uma questão de identidade.

Segundo Norton (2000), a identidade é definida pela maneira como o indivíduo entende sua relação com o mundo, as possibilidades para o futuro, e como essa relação é construída através do tempo e espaço. As identidades são determinadas contextualmente e são o resultado de várias interpretações culturais de raça, gênero, classe social, religião e sociedade. No caso da identidade de professor não nativo de inglês, as diferenças são produzidas ambientalmente ao invés de herdadas. $\mathrm{Na}$ busca de construir sua própria identidade, o professor não nativo se depara com visões conflitantes relacionadas a padrões da língua, pronúncia "correta" e modelos a seguir, que podem facilmente levá-lo a uma auto-avaliação negativa de si mesmo. O papel das universidades aqui é mais uma 
vez crucial, pois em sala de aula ou durante o período das aulas de estágio, essas crenças podem ser reafirmadas ou transformadas. Portanto, reforço a utilidade de discutir esse assunto durante a formação dos professores, ainda na universidade, o que aumenta as possibilidades de um maior equilíbrio de identidade dos professores de inglês.

Nemtchinova (2010) conduziu uma pesquisa com professores universitários que ministram a disciplina de estágio e que possuem alunos cuja língua materna é o inglês e também alunos falantes não nativos de inglês. O objetivo deste estudo foi verificar se a percepção dos professores da disciplina de estágio a respeito de seu alunos era influenciada pelas nacionalidades dos estagiários. Os resultados mostraram que não houve uma diferença estatisticamente significante entre as performances dos alunos nativos e não nativos, com exceção de um item: conhecimento cultural. As categorias listadas foram: qualidades pessoais, domínio da língua, organização da aula, aplicação da aula, feedback para os alunos e autoavaliação. As pontuações se mantiveram entre bom e excelente em todos os itens, exceto a questão da cultura em sala de aula, como mencionado anteriormente. Esse estudo dentre tantos outros sobre o professor de inglês não nativo (MAHBOOB, 2010; TATAR E YILDIZ, 2010) vem para reafirmar que em diversos pontos, o professor não nativo está igualmente capacitado para atuar no ensino de inglês, trazendo consigo características que enriquecem a sala de aula. Nemtchinova (2010) ressalta a satisfação dos alunos em enxergar seu professor como alguém que alcançou a fluência na língua embora seja como um deles, um falante não nativo.

Suarez (2005) afirma que o tema "falantes nativos vs. falantes não nativos" não possui destaque em colóquios e eventos sobre ensino de língua inglesa talvez por ser um "calo" que é mais fácil neutralizar do que tratar. O que se encontra atualmente é o 
discurso que ambas as posições dessa dicotomia trazem suas contribuições, complementando um ao outro e coexistindo em harmonia (ibid.).

\section{Considerações finais}

Assim, caminha-se para a necessidade de reflexão por parte dos professores de LE em relação ao seu papel em sala de aula, não como embaixadores dos países do norte, mas sim como agentes de transformação, pois de acordo com Freire (1985), a língua e o letramento são mecanismos - chave para reconstrução social. Ajudar os alunos a se tornarem letrados criticamente inclui tornálos capazes de detectar e lidar com a dimensão ideológica inerente na língua e letramento, posto que o letramento é uma pratica social e política ao invés de um grupo de habilidades psicológicas neutras.

O conceito de língua dentro do Letramento Crítico e o importante papel do professor não-nativo de inglês se encaixam perfeitamente no cenário atual, dentro do qual a língua inglesa ganha a cada dia mais validação do status de global e torna-se uma ferramenta de reflexão e construção de sentidos. Como supracitado, o conflito é muito bem-vindo dentro do LC, ao contrário da abordagem comunicativa que o encara como algo a ser evitado. Neste conflito encontra-se a oportunidade para construção de novos conhecimentos e transformação de procedimentos interpretativos e de visões de mundo (JORDÃO, 2007).

O professor que trabalha a partir do Letramento Crítico aborda a questão da representação, ou seja, questiona quem constrói os textos cujas representações são dominantes em uma cultura e em uma época particular e quem é beneficiado por estas representações. Neste contexto, no qual a língua inglesa assume o papel de global com objetivos que se afastam a cada dia mais do 
domínio e valorização dos países do norte, e o Letramento Crítico trazendo a reflexão e consciência do porquê estudar uma língua estrangeira, não há razão para que o professor não nativo de inglês sinta-se em uma posição menos valorizada ou seu trabalho seja considerado de qualidade inferior do trabalho de um professor nativo. A aceitação como professor não nativo de inglês pode estar ligada ao conhecimento sobre os aspectos da atualidade mencionados anteriormente, e consequentemente, a valorização do professor nativo em detrimento do nãonativo está ligada à falta de conhecimento sobre inglês como língua global e sobre a proposta do Letramento Crítico já difundida pelas OCEM (BRASIL, 2006). 


\section{Referências}

ANDREOTTI, V. \& MARIO, L. Global Learning in the Knowledge society- Four tools for discussion. Revista ZEP, 2008.

BERNATT, E. Towards a pedagogy of empowerment: The case of the Impostor Syndrome among pre-service non-nativespeaker teachers in TESOL. Revista ELTED, 2008.

BERNATT, E. Entrevista concedida ao blog Non Native English Speaker of the month publicada em 24 de abril de 2009. <http://nnesintesol.blogspot.com.br/2009/04/eva-bernat. html > Acesso em junho 2013.

BRASIL . Orientações curriculares para o ensino médio: Linguagens, códigos e suas tecnologias. Brasília: Secretaria de Educação Básica, Ministério da Educação, 2006.

CRYSTAL, D. English as a global language. 2. Ed. Cambridge: Cambridge University Press, 2010.

JENKINS, J. Which pronunciation norms and models for English as an International Language? ELT Journal52/2. Oxford University Press, 1998.

JORDÃO, C. M. A posição do inglês como língua internacional e suas implicações para a sala de aula. in Inglês como língua franca: Ensino- aprendizagem e formação de professores. GIMENES, T., CALVO, L. C. S., EL KADRI, M. S. Campinas, SP: Pontes Editores, 2011.

JORDÃO, C. M. A posição de professor de inglês no Brasil: Hibridismo, Identidade e Agencia. MG, Uberlandia, Revista Letras \& Letras, 2010.

JORDÃO, C. M. O que todos sabem ou não... Letramento crítico e questionamento conceitual. Revista Crop. Universidade de São Paulo, 2007. 
JORDÃO, C. M. \& FOGAÇA, F.C. Ensino de Inglês, Letramento Crítico e Cidadania: Um triangulo amoroso bemsucedido. Revista Línguas \& Letras, Universidade Estadual do Oeste do Paraná, 2007.

LLURDA, E. Non-native-speaker teacher and English as an International Language. International journal of Applied Linguistics, v.14, n. 1, p. 314-323, 2004.

MAHBOOB, A. The NNEST Lens: Non Native English Speakers in TESOL. Cambridge Scholars Publishing, 2010.

MATTOS, A. M. A e VALÉRIO, K. M. Letramento crítico e ensino comunicativo: lacunas e interseções. $R B L A$, Belo Horizonte, v. 10, n. 1, p. 135-158, 2010.

NEMTCHINOVA, E. The "Who's worth more?" Question revisited: MA TEASOL Practicum. Host teachers' perceptions of NES and NNES Teacher Trainees. Em MAHBOOB, A. The NNEST Lens: Non Native English Speakers in TESOL. Cambridge Scholars Publishing, 2010.

NORTON, B. Identity and Language Learning: Gender, Ethnicity and Educational Change. London, Longman/ Pearson Education, 2000.

RAJAGOPALAN, K. O “World English” - Um fenômeno muito mal compreendido. In: Inglês como língua franca: Ensino- aprendizagem e formação de professores. GIMENES, T., CALVO, L. C. S., EL KADRI, M. S. Campinas, SP: Pontes Editores, 2011.

RICHARDS, J. e ROGERS, T. S. Approaches and methods in Language Teaching. Cambridge University Press: Cambridge, 1986.

Selvi, A. F. 2010. 'All teachers are equal, but some teachers are more equal than others: trend analysis of job advertisements in English language teaching'. WATESOL NNEST Caucus Annual Review 1: 156-81. Disponível em: <https://sites. google.com/site/watesolnnestcaucus/caucus-annual-review $>$. 
SIQUEIRA, S. Inglês como língua franca: O desafio de ensinar um idioma desterritorializado. In: Inglês como língua franca: Ensino- aprendizagem e formação de professores. GIMENES, T., CALVO, L. C. S., EL KADRI, M. S. Campinas, SP: Pontes Editores, 2011.

SUAREZ, J. "Native" and "non-native": not only a question of terminology'. Humanizing Language. Teaching 2/6. 2005. Disponível em <http://www.hltmag.co.uk/nov00/mart1.htm>. Acesso julho 2013.

TATAR, S. \& YILDIZ, S. Empowering Nonnative -English Speaking Teacher in the Classroom. Em MAHBOOB, A. The NNEST Lens: Non Native English Speakers in TESOL. Cambridge Scholars Publishing, 2010.

Recebido em 27/02/2014 Aceito para publicação em 23/07/2014 